\title{
Prospecção Tecnológica sobre Métodos de Tratamento de Água Contendo Corantes e Pigmentos
}

\author{
Technological Prospection on Treatment Methods for Water Containing \\ Dyes and Pigments
}

\author{
José Luiz Cunha Cordeiro ${ }^{1}$ \\ Suzana Modesto de Oliveira Brito ${ }^{2}$ \\ ${ }^{1}$ Universidade Federal da Bahia, Salvador, BA, Brasil \\ ${ }^{2}$ Universidade Estadual de Feira de Santana, Feira de Santana, BA, Brasil
}

\begin{abstract}
Resumo
Este trabalho tem como objetivo a busca de anterioridade sobre métodos de tratamentos de água contendo corantes e pigmentos utilizando as bases de dados Espacenet e ScienceDirect. A metodologia consistiu na associação das palavras dye*, pigment*, treatment*, water* e method*, encontrando um total de 296 patentes e 25.792 trabalhos de divulgação científica. A China, o Reino Unido e os Estados Unidos foram os países que mais se destacaram no depósito de patentes relativas ao tema, indicando que tais países estão seguros com a apropriação de seus conhecimentos. A partir da análise das patentes, verificou-se que os métodos para a remoção de corantes e de pigmentos do meio aquoso são pouco explorados, tendo alto potencial para gerar inovação. A partir da análise dos trabalhos científicos publicados, verificou-se que existe um grande número de publicações referentes ao tema e que os artigos originais são a sua forma de maior divulgação.
\end{abstract}

Palavras-chave: Corantes. Tratamento de água. Pigmentos.

\begin{abstract}
This work aims to search for treatment methods for water containing dyes and pigments using the Espacenet and ScienceDirect databases. The methodology consisted in associating the words dye *, pigment *, treatment *, water * and method * finding 296 patents and 25,792 works of scientific dissemination. China, United Kingdom and the United States were the most prominent countries in filing patents on the subject, indicating that such countries are safe in the appropriation of their knowledge. From the analysis of the patents it was verified that the methods for removal of dyes and pigments from water still little explored, having high potential to generate innovation. From the analysis of published scientific papers it was verified that there is a large number of publications related to the topic, and that the original articles are the most publicized form on the subject.
\end{abstract}

Keywords: Dyes. Water Treatment. Pigments.

Área Tecnológica: meio ambiente, tratamento de efluentes. 


\section{Introdução}

Atualmente, diversas indústrias usam corantes na fabricação de seus produtos, sendo que as indústrias têxteis, de curtumes, indústrias de papel e de alimentos se destacam no uso de corantes, e em geral os corantes sintéticos são mais utilizados que os corantes naturais por causa de suas vantagens (KYZAS; FU; MATIS, 2013). A produção anual de corantes sintéticos atinge 700.000 toneladas por ano e cerca de 10 a $15 \%$ desses corantes chegam aos efluentes, comprometendo, assim, os corpos d'água. Só a indústria têxtil libera aproximadamente 100 toneladas por ano de corantes nos efluentes aquosos (KHARAT, 2015; YAGUB; SEN; ANG, 2012).

Os pigmentos também são poluentes preocupantes, por possuírem propriedades físicas, químicas e biológicas que fazem com que sejam compostos de difícil tratamento e controle, afetando não somente os ecossistemas, mas também a vida humana (LODHI; LAL, 2017). Os pigmentos sintéticos também são produzidos em larga escala no mundo, possuindo amplo uso na indústria têxtil e no processamento de papéis, medicamentos, cosméticos, fotos, alimentos e suplementos alimentares, sendo que os mais de 200 tipos diferentes de pigmentos em uso constituem mais da metade de todos os corantes do mundo (ELBANNA et al., 2017).

Os corantes e pigmentos quando liberados nos corpos d'água produzem uma cor indesejada, reduzindo os processos de fotossíntese e prejudicando a vida aquática (YAGUB et al., 2014). Esses compostos podem causar alergias, dermatites, irritações na pele e até mesmo o câncer, dependendo da concentração e do tempo de exposição (YAGUB; SEN; ANG, 2012).

As classes de corantes geralmente utilizadas nas indústrias incluem os corantes ácidos, básicos, diretos, dispersos, mordentes, reativos, sulfonados, azóicos e corantes de tina (vat dyes). $\mathrm{O}$ grau de toxicidade desses corantes varia muito. Em geral, os corantes catiônicos são mais tóxicos, seguidos pelos aniônicos. Os corantes diretos possuem o menor nível de toxicidade. A mistura de corantes nos efluentes pode apresentar efeitos sinérgicos, potencializando a toxicidade do material final (WALTHALL; STARK, 1999).

Nesse cenário, o desenvolvimento de métodos de tratamento para a remoção de corantes e pigmentos de efluentes está sendo estudada constantemente. Os processos mais utilizados para a descoloração de efluentes são a coagulação, floculação, biodegradação, adsorção, separação com membranas, troca iônica, processos oxidativos avançados, entre outros (SUN; YANG, 2003).

Este trabalho tem como objetivo a busca de anterioridade sobre métodos de tratamentos de água contendo corantes e pigmentos utilizando as bases de dados Espacenet e ScienceDirect. A prospecção tecnológica a respeito deste conteúdo é de extrema importância, pois, com ela, é possível mapear os desenvolvimentos científicos e tecnológicos a respeito do conteúdo, bem como identificar oportunidades para o desenvolvimento tecnológico. A busca de anterioridade permite avaliar o estado atual da tecnologia em estudo, tanto em termos e estágios de desenvolvimento como em termos de apropriação (QUINTELLA et al., 2011). Além disso, a busca por trabalhos científicos e patentes sobre o assunto permite o estabelecimento do estado da arte sobre tratamento de água contendo corantes e pigmentos, fazendo com que a busca por novos processos e materiais alternativos para o tratamento de água seja otimizada.

A Espacenet é uma base de dados mantida pelo Escritório Europeu de Patentes (EPO European Patents Office) e contém mais de 90 milhões de documentos de patentes de diversos países, sendo mais abrangente que o site do Escritório Americano de marcas e Patentes (USPTO - United States Patent Office), que só apresenta as patentes registradas nos Estados Unidos e o 
LATIPAT que contém dados sobre patentes de países da América Latina (BASE DE PATENTES ONLINE, 2019). O ScienceDirect é uma base de dados de publicações científicas operada pela Editora Elsevier reunindo mais de 3.800 revistas com conselho editorial e publicações revisadas por pares, além de mais de 35.000 títulos de livros (SCIENCDIRECT, 2019). Essas bases de dados foram escolhidas para a pesquisa realizada neste artigo por serem consideradas pelos autores as bases de dados mais abrangentes e confiáveis de acesso on-line.

A prospecção de trabalhos científicos no tema tratamentos de água contendo corantes e pigmentos é especialmente importante quando se busca investigar novos materiais para utilização nos processos de descontaminação, visto que a purificação de água contendo corantes e/ou pigmentos geralmente envolve processos de alto custo. A busca por novos materiais envolve sempre uma etapa de seleção de produtos e o conhecimento do que existe publicado e/ ou patenteado ajuda a estreitar o campo de busca, otimizando o tempo empregado na escolha dos materiais a serem estudados. Isso possibilita não só uma melhor elaboração de projetos de pesquisa básica, como pode levar a obtenção de novos materiais por modificação daqueles já existentes. Como esse tipo de trabalho geralmente envolve uma grande quantidade de pesquisa básica sobre propriedades de materiais, métodos de síntese e formas de utilização, a busca de anterioridade não deve se limitar a patentes, necessitando envolver também publicações científicas recentes na área, para que se obtenha um panorama do que vem sendo estudado, possibilitando o desenvolvimento de trabalhos inéditos sobre o tema.

\section{Metodologia}

A busca por documentos de patentes foi realizada no banco de dados Espacenet, que é uma base mundial de acesso livre usualmente empregada em trabalhos de prospecção (SILVA; CID; QUINTELLA, 2015). A busca pelas patentes foi realizada de forma a prover o maior número de documentos de patentes referentes ao tema de estudo, utilizando palavras-chave que tornassem possível uma pesquisa representativa sobre o tema. A coleta de dados foi realizada em 22 de janeiro de 2019. A Tabela 1 mostra o escopo utilizado para a pesquisa dos documentos de patentes:

A metodologia consistiu na associação das palavras-chave Dye*, Pigment*, Treatment*, Water*, Method*. Essas palavras-chave foram escolhidas para atender aos objetivos desse trabalho, tendo sido definidas após uma etapa de revisão bibliográfica, onde se verificou que estavam presentes nos títulos das publicações consultadas. Com essa combinação foram encontrados 296 documentos de patentes. Após a eliminação das repetições e a remoção de patentes que não eram o foco deste trabalho, 285 famílias de patentes foram analisadas. A utilização dessas palavras-chave foi planejada para mapear o maior número de patentes e meios de divulgação científica possíveis. A utilização do asterisco após a palavra-chave tem o objetivo de estender a busca dos termos ao singular e plural.

Observa-se que para a busca com os termos individuais e para a combinação dos termos Dye*e Pigment*, foi obtido um número indeterminado de resultados, com a indicação pela base de dados Espacenet de mais de 10.000 resultados, sem quantificação exata. Só foi obtida uma quantificação exata de documentos a partir da combinação de três ou mais palavras-chave na busca. Isso é devido à generalidade das palavras escolhidas, quando utilizadas individualmente, já que os resultados incluem documentos referentes à invenção, fabricação de materiais, tratamentos diversos e não apenas de água contendo corantes e pigmentos, além de diversos métodos não relacionados ao escopo deste trabalho. 
Tabela 1 - Pesquisa por palavra-chave no Espacenet

\begin{tabular}{|c|c|c|c|c|c|}
\hline$D_{Y E^{* A}}$ & PIGMENT *в & TREATMENT*c & WATER $^{* \mathrm{D}}$ & METHOD* & TOTAL \\
\hline \multirow[t]{5}{*}{$X$} & & & & & Mais de 10.000 \\
\hline & $\mathrm{X}$ & & & & Mais de 10.000 \\
\hline & & $\mathrm{X}$ & & & Mais de 10.000 \\
\hline & & & $\mathrm{X}$ & & Mais de 10.000 \\
\hline & & & & $\mathrm{X}$ & Mais de 10.000 \\
\hline $\mathrm{X}$ & $\mathrm{X}$ & & & & Mais de 10.000 \\
\hline $\mathrm{X}$ & $\mathrm{X}$ & $\mathrm{X}$ & & & 1705 \\
\hline $\mathrm{X}$ & $\mathrm{X}$ & $\mathrm{X}$ & & $\mathrm{X}$ & 628 \\
\hline$X$ & X & $X$ & $X$ & $X$ & 296 \\
\hline
\end{tabular}

aCorante; 'Pigmento; 'Tratamento; 'Água; 'Método

Fonte: Elaborada pelos autores deste artigo (2019)

A busca de artigos e outros meios de divulgação científica foi feita utilizando a base de dados ScienceDirect, associando as mesmas palavras utilizadas para a pesquisa no Espacenet. A coleta de dados foi realizada em 3 de fevereiro de 2019, de forma a prover o maior número de artigos e outros meios de divulgação existentes, não sendo estabelecido limitação do período. A Tabela 2 mostra o escopo utilizado na base de dados ScienceDirect. A busca no ScienceDirect possibilitou a quantificação mais detalhada das publicações, tendo em vista que esta base de dados trabalha com meios de divulgação diferentes dos documentos de patentes. É interessante observar que, mesmo tendo uma quantificação mais exata, o número de resultados obtidos para a busca pelos termos individuais é ainda muito grande, especialmente para as palavras-chave Treatment*, Water* e Method* que podem ser considerados como pouco específicos para o escopo desse trabalho. A medida em que se aumenta a combinação entre as palavras, a busca se estreita, levando a resultados mais pertinentes ao tema.

Tabela 2 - Pesquisa por palavra-chave no ScienceDirect

\begin{tabular}{|c|c|c|c|c|c|}
\hline DYE* & PIGMENT* & TREATMENT* & WATER* & METHOD* & TOTAL \\
\hline \multirow[t]{5}{*}{$\mathrm{X}$} & & & & & 678.423 \\
\hline & $X$ & & & & 319.176 \\
\hline & & $\mathrm{X}$ & & & 6.250 .213 \\
\hline & & & $\mathrm{X}$ & & 4.691 .063 \\
\hline & & & & $\mathrm{X}$ & 10.859 .202 \\
\hline$X$ & $X$ & & & & 57.248 \\
\hline $\mathrm{X}$ & $\mathrm{X}$ & $\mathrm{X}$ & & & 35.714 \\
\hline$X$ & $X$ & $X$ & $\mathrm{X}$ & & 27.536 \\
\hline $\mathrm{X}$ & $X$ & $X$ & $\mathrm{X}$ & $\mathrm{X}$ & 25.792 \\
\hline
\end{tabular}

aCorante; ${ }^{\mathrm{b} P i g m e n t o ; ~ ' T r a t a m e n t o ; ~}$ dÁgua; ${ }^{\text {Método }}$

Fonte: Elaborada pelos autores deste artigo, 2019 


\section{Resultados e Discussão}

A Figura 1 apresenta a distribuição de depósito ao longo do tempo, entre os anos 1906 e 2018, sem restrição por país. Os dados obtidos após o refinamento do total encontrado foram analisados para diversos aspectos pertinentes à prospecção científica, sempre tendo em foco o tema métodos de tratamento de corantes e pigmentos em meio aquoso.

A primeira patente a ser depositada sobre esse tema, no ano de 1906, no Reino Unido, tinha como titular Leon Lilienfeld. Entre 1906 e 1994, houve depósito de várias patentes, porém foram depositadas poucas patentes por ano e em alguns anos desse intervalo não houve depósito de patentes. Tal fato pode estar associado a falta de preocupação com a água potável nesta época, visto que esse assunto começou a ganhar uma maior visibilidade a partir do ano de 1977 com a Declaração Ministerial de Haia (Países Baixos) sobre segurança da água no século XXI, onde foram registradas as ações e discussões em Mar Del Plata. Tal discussão continuou em Dublin e foram consolidadas no Capítulo 18 da Agenda 21 no Rio em 1992. Essas ações foram reafirmadas em Paris em 1998, CDS-6 e no segundo Fórum Mundial da Água e na Conferência Ministerial (DETONI; DONDONI, 2008).

Observa-se que o tema começou a receber um depósito significativo de patentes a partir do ano de 1995, como pode ser visto na Figura 2. Esse depósito de patentes deve-se ao fato de que o problema da poluição aquática começou a chamar a atenção da sociedade, devido ao seu caráter global e imediato, e como os corantes e pigmentos são compostos classificados como poluentes de elevado risco, devido a sua difícil biodegradação e resistência aos tratamentos convencionais, o desenvolvimento de novas tecnologias para a remoção desses compostos fez-se necessária(BRITO et al., 2010).

Figura 1 - Evolução anual do depósito de patentes conforme escopo deste trabalho de 1906 a 2018

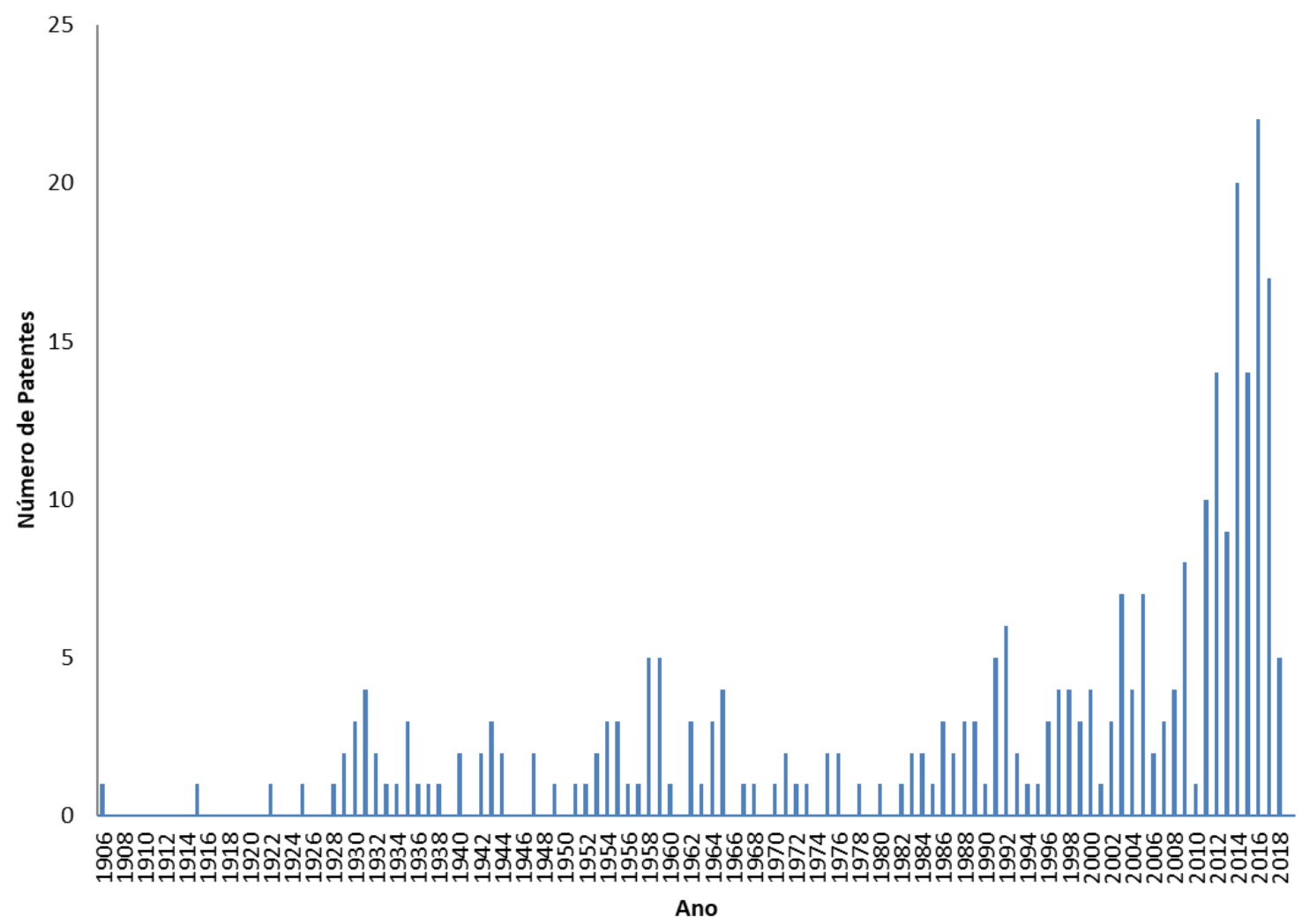

Fonte: Elaborada pelos autores deste artigo (2019) 
A Figura 2 apresenta a evolução anual do depósito de patentes conforme escopo deste trabalho a partir de 1995. Apesar de as Figuras 1 e 2 apresentarem os mesmos dados, a Figura 2 mostra os trabalhos depositados a partir de 1995 de uma forma ampliada, o que facilita a interpretação dos resultados. Como essa prospecção pretende construir um panorama de métodos de tratamento de água contendo corantes e pigmentos, com o objetivo de subsidiar a pesquisa de novos métodos e matérias, a visão mais detalhada dos documentos de patentes mais atuais fornece dados para avaliar como a pesquisa sobre o tema vem evoluindo, considerando que as informações mais atuais representam melhor o estado da arte sobre o assunto.

Figura 2 - Evolução anual do depósito de patentes conforme escopo deste trabalho a partir de 1995

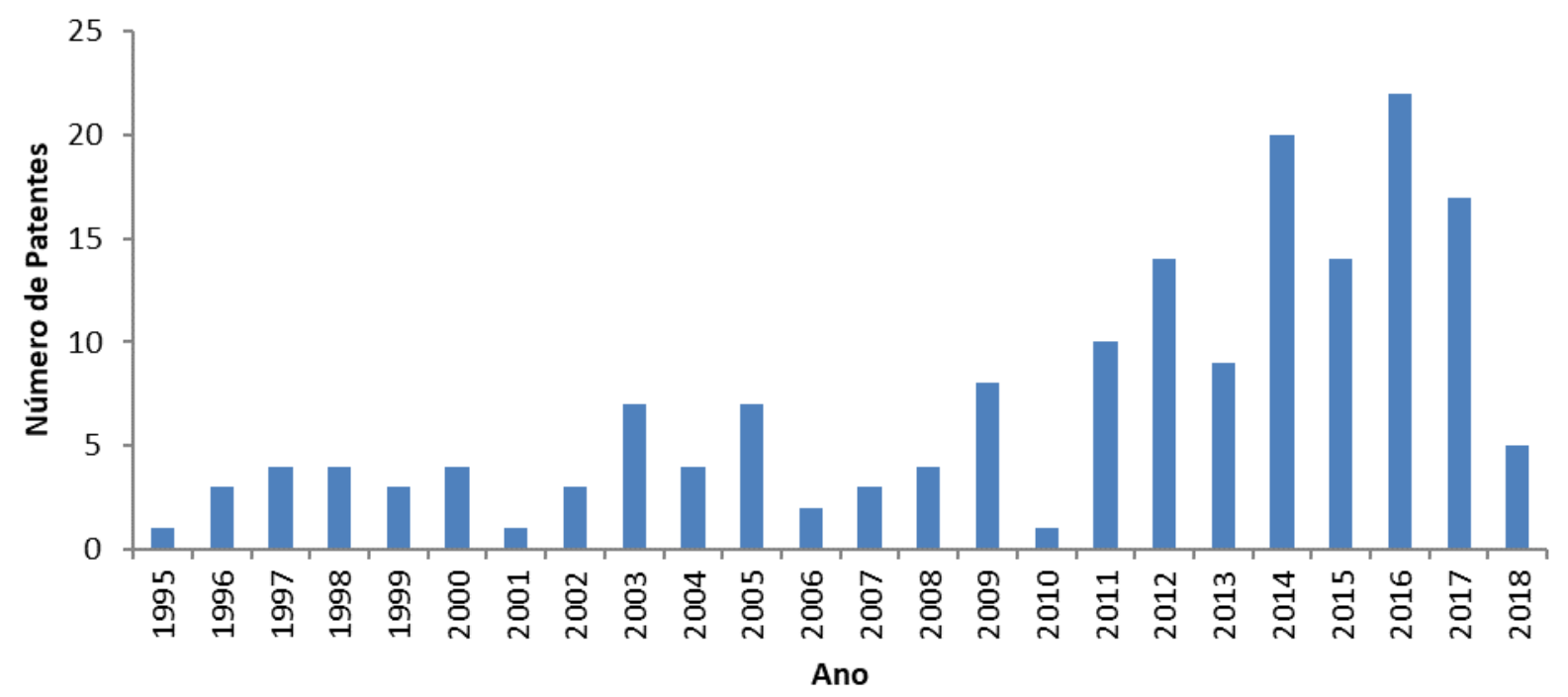

Fonte: Elaborada pelos autores deste artigo (2019)

Ao se analisar a evolução dos depósitos de patentes a partir de 1995 (Figura 2), observa-se cinco bandas de crescimento no depósito de patentes. A primeira banda foi entre os anos 1995 e 2000, tendo sido atingida quatro patentes no ano 2000, a segunda entre 2001 e 2005 com sete patentes em 2005, a terceira entre 2006 e 2009 com oito patentes em 2009, a quarta entre 2010 e 2012 com 14 patentes em 2012 e a última entre 2013 e 2016 com o depósito de 22 patentes em 2016, sendo que o ano de 2016 foi o ano em que mais houve depósitos de patentes. Isso pode ser atribuído ao fato de que a situação da água doce no planeta é muito preocupante, devido ao crescimento da poluição aquática e como os corantes e pigmentos são poluentes aquosos perigosos, o desenvolvimento de métodos para a remoção desses poluentes é de extrema importância (BRITO et al., 2010). A falta de documentos de patentes a partir de 2019 se deve ao fato de não se dispor de informações completas por causa do período de sigilo de patentes, que é de 18 meses.

A Figura 3 mostra a distribuição de patentes depositadas por países e organizações. O país que mais se destacou no domínio tecnológico de métodos de tratamento de corantes e pigmentos em meio aquoso foi a China, com um total de 114 patentes. Isso pode estar relacionado ao fato de que a China possui uma cultura muito forte de propriedade intelectual (SILVA; CID; QUINTELLA, 2015). Além disso, a China vem se destacando em quase todos os setores, devido a forte política de inovação tecnológica presente no país (CUNHA, 2017). Após a China, o país que mais se destacou no depósito de patentes relativas a esta prospecção, foi o Reino Unido com um total de 79 famílias de patentes, seguido pelo Japão com 59 registros de patentes. 
Após China, Reino Unido e Japão, os países que mais se destacaram no depósito de patentes relativas a este tema foram Estados Unidos da América, com oito patentes; República da Coreia, com seis patentes; Federação Russa, com cinco patentes; Alemanha com três patentes e França e Suiça com duas patentes cada, respectivamente. O Brasil não possui patentes depositadas sobre esse tema.

Figura 3 - Países e organizações que mais detêm patentes na área em estudo

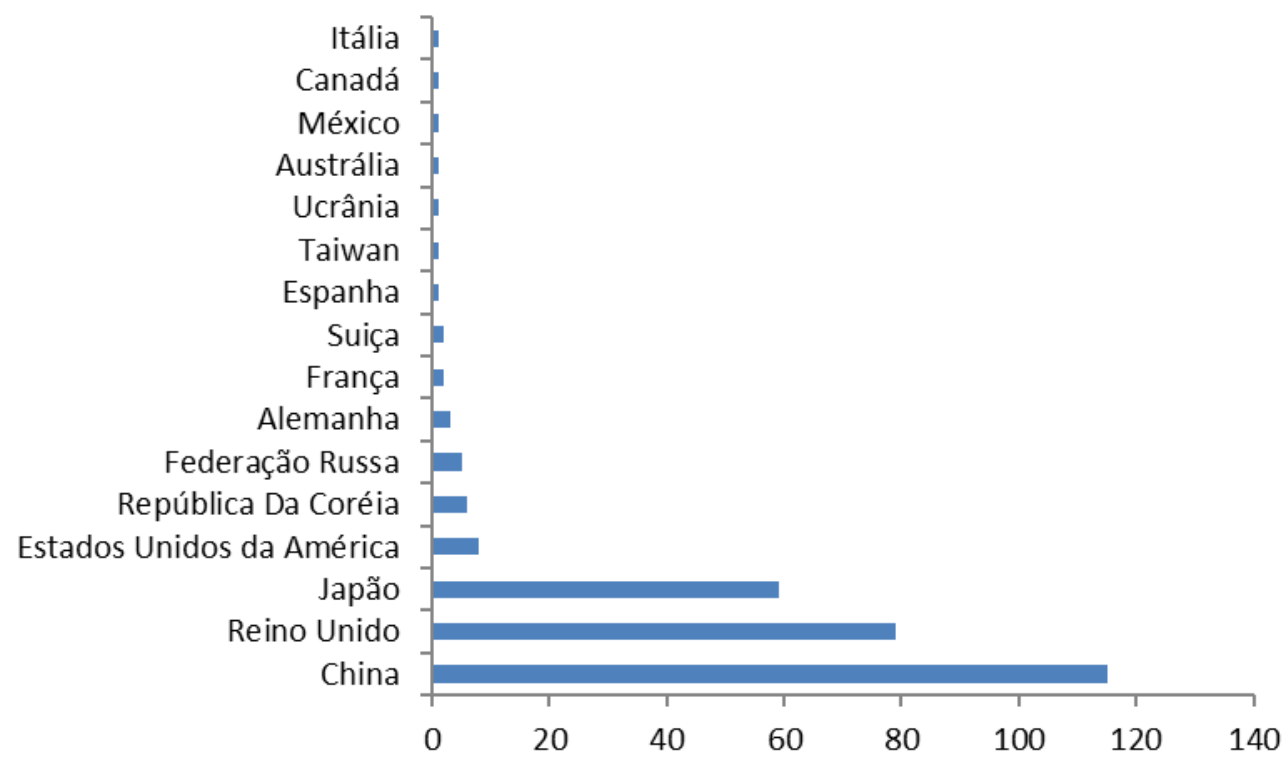

Fonte: Elaborada pelos autores deste artigo (2019)

Não foi possível encontrar no ScienceDirect o primeiro trabalho científico relativo ao tema, mas observa-se que existe um aumento exponencial a partir do ano de 1995 conforme mostra a Figura 4. Ao se analisar a evolução das publicações de trabalhos de divulgação científica, observa-se que existe uma única banda de crescimento de trabalhos relativos a esse tema, tendo sido publicados 1884 trabalhos de divulgação científica no ano de 2018. Isso pode ser devido ao fato de que esse tema vem chamando a atenção de diferentes cientistas de áreas distintas da ciência, devido ao problema ambiental que é o despejo de corantes nos corpos d'água (BRITO et al., 2010).

Figura 4 - Evolução anual da publicação de trabalhos de divulgação científica conforme escopo deste trabalho

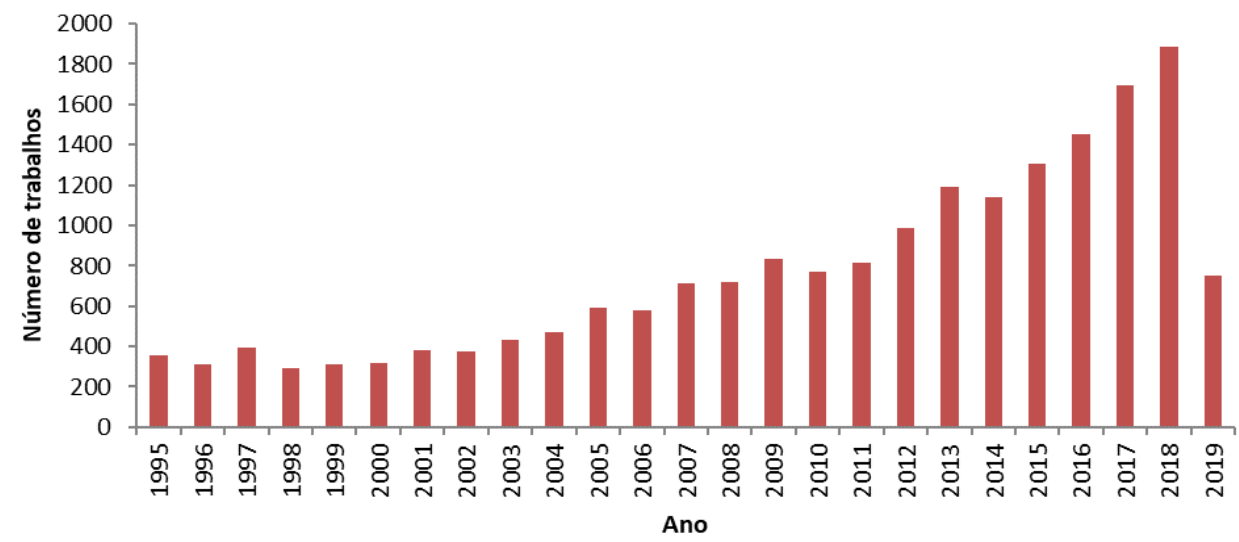

Fonte: Elaborada pelos autores deste artigo (2019) 
Na Figura 5, pode-se ver que o setor da sociedade que mais se destacou no depósito de patentes referentes a esse tema foi o empresarial (71\%), seguido de pessoas físicas (16\%) e das Universidades (13\%). A maior porcentagem de depósito de patentes referentes a métodos de tratamento de corantes e pigmentos em meio aquoso ainda se concentra no setor empresarial, atraindo de uma forma parcial os outros setores da sociedade.

Figura 5 - Setores da sociedade aos quais pertencem os titulares das patentes

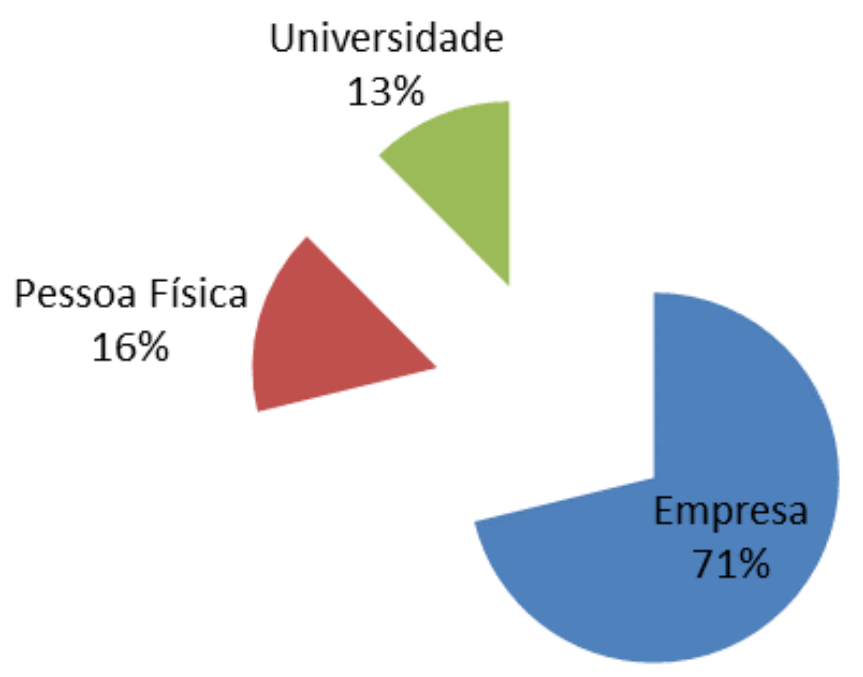

Fonte: Elaborada pelos autores deste artigo (2019)

A Figura 6 mostra os principais titulares e o número de patentes de cada um deles. A figura mostra apenas os titulares com três ou mais patentes depositadas. No entanto, a maioria das empresas, Universidades e pessoas físicas localizadas nessa busca depositou uma ou duas patentes.

Figura 6 - Principais titulares de documentos de patentes a partir de 1906

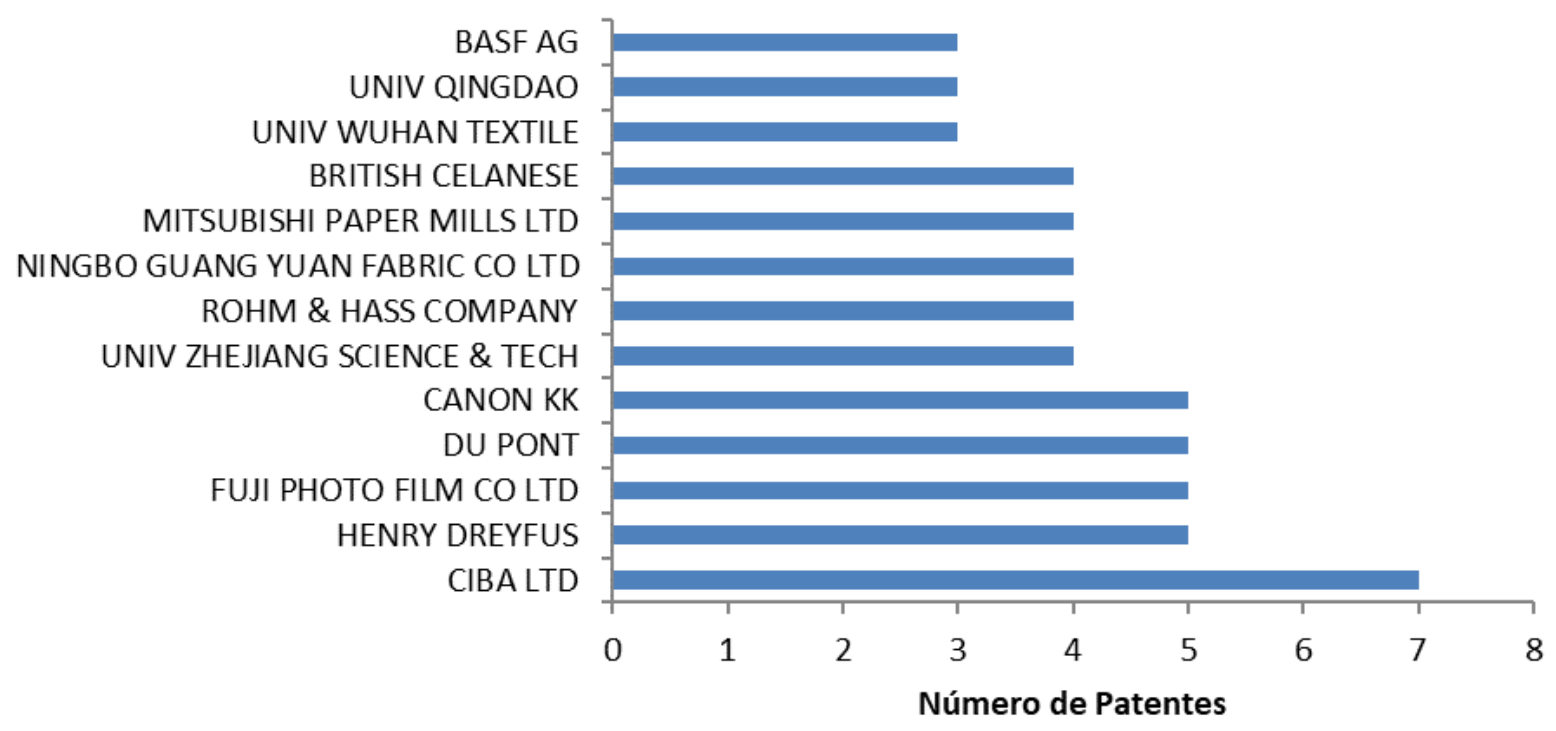

Fonte: Elaborada pelos autores deste artigo (2019)

A distribuição da titularidade das patentes por empresa mostra que a empresa Ciba LTD é a que mais se destaca no depósito de patentes relativos a este tema, com um total de sete 
patentes, sendo que essas patentes foram depositadas no Reino Unido. A empresa Ciba AG surgiu na década de 1850 como uma empresa de tingimento de seda e estendeu sua atuação a produtos farmacêuticos em 1900, época em que era a maior indústria química na Suíça. Na década de 1970 sofreu fusão com a J.R. Geigy SA se tornando também uma fábrica de corantes para a indústria têxtil. Entrou no mercado farmacêutico em 1930 e em 1996 sofre fusão com a companhia Suíça Sandoz, formando a Novartis AG, uma das maiores companhia de produtos farmacêuticos do mundo (ENCYCLOPEDIA BRITANNICA, 2019).

A pessoa física que se destacou em número de patentes foi Henry Dreyfus com cinco patentes também no Reino Unido. Henry Dreyfus era filho de um industrial suíço, da área química. Entre suas invenções, encontram-se uma forma sintética do corante índigo carmim e o desenvolvimento do acetato de celulose, além do desenvolvimento de vários outros corantes sintéticos. Durante sua vida, Henry Dreyfus depositou mais de 2.000 documentos de patentes (DREYFUS FOUNDATION, 2019).

A Tabela 3 mostra titulares com depósito de duas patentes. Um total de cinco empresas, três universidades e uma pessoa física depositaram duas patentes. Entre as empresas, uma patente foi depositada no Reino Unido, três patentes na China e duas patentes no Japão. As duas patentes relativas as Universidades e a patente relativa à pessoa física foram depositadas na China.

Tabela 3 - Titulares com depósito de duas patentes

\begin{tabular}{ccc} 
TitulaRes & Setor Da Sociedade & País \\
AMERICAN CYANAMID CO & Empresa & Reino Unido \\
CHANGZHOU YUNQING BIOTECHNOLOGY CO LTD & Empresa & China \\
DAINICHISEIKA COLOR CHEM & Empresa & Japão \\
GUANGDONG JUN AN JEANS RES INST & Empresa & China \\
JIANGSU COLLEGE OF ENGINEERING AND TECH & Universidade & China \\
KONISHIROKU PHOTO IND & Empresa & Japão \\
UNIV SHANGHAI JIAOTONG & Universidade & China \\
UNIV TIANJIN POLYTECHNIC & Universidade & China \\
ZICONG SHI & Pessoa Física & China \\
\hline
\end{tabular}

Fonte: Elaborada pelos autores deste artigo (2019)

Na Tabela 2 mostrada anteriormente, viu-se que mais de 25000 trabalhos de divulgação científica foram encontrados sobre métodos de tratamento de corantes e pigmentos em meio aquoso. Quando se analisa o tipo de publicação, observa-se que a publicação de artigos científicos (59\%) é a que mais se destaca, seguido de capítulos de livros (19\%), outros tipos de publicação $(12 \%)$, artigos de revisão $(8 \%)$ e enciclopédia (2\%). Os meios de divulgação colocados sob a categoria "outros", consistem em minirrevisões, anais de eventos, críticas, comunicações em congressos, erratas etc. A Figura 7 mostra essa distribuição. 
Figura 7 - Meios de divulgação científica aos quais pertencem os trabalhos

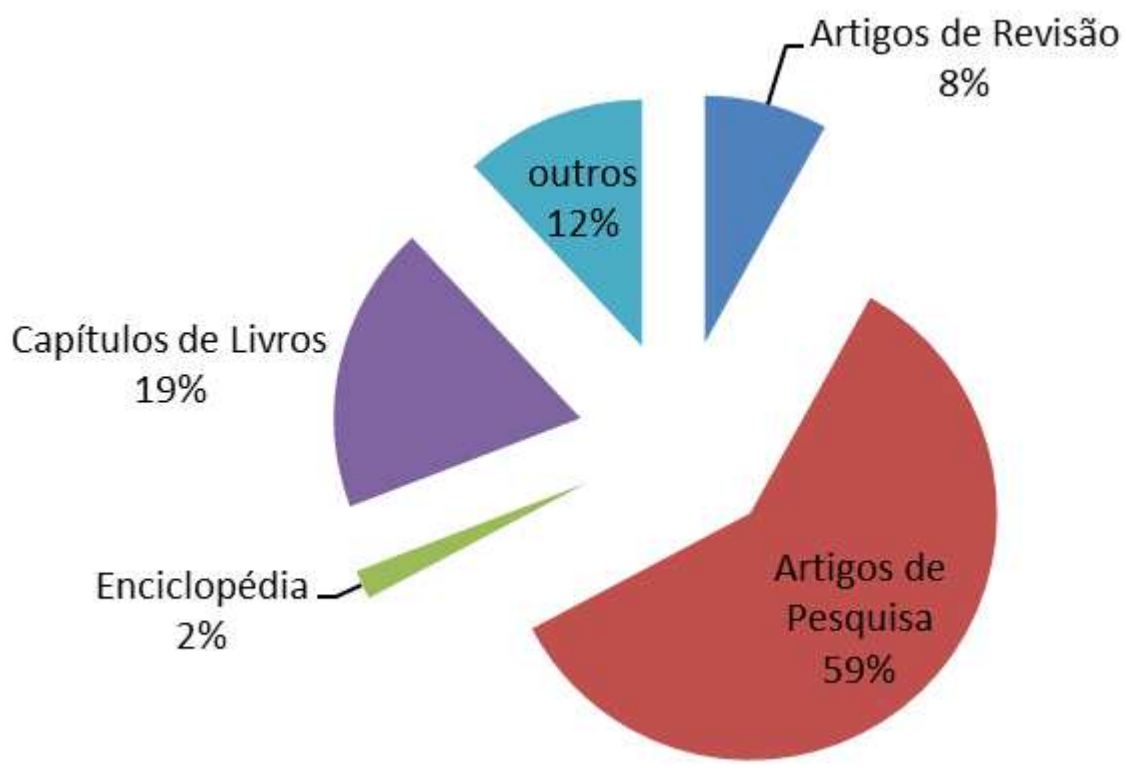

Fonte: Elaborada pelos autores deste artigo (2019)

Entre os meios de divulgação científica algumas revistas se destacaram na publicação de artigos referentes a este tema. A revista que mais teve publicações no tema foi Dyes e Pigments com um total de 2003 trabalhos científicos. A Figura 7 mostra as revistas que mais publicaram artigos referentes a este tema:

Figura 7 - Revistas que mais publicaram na área de estudo

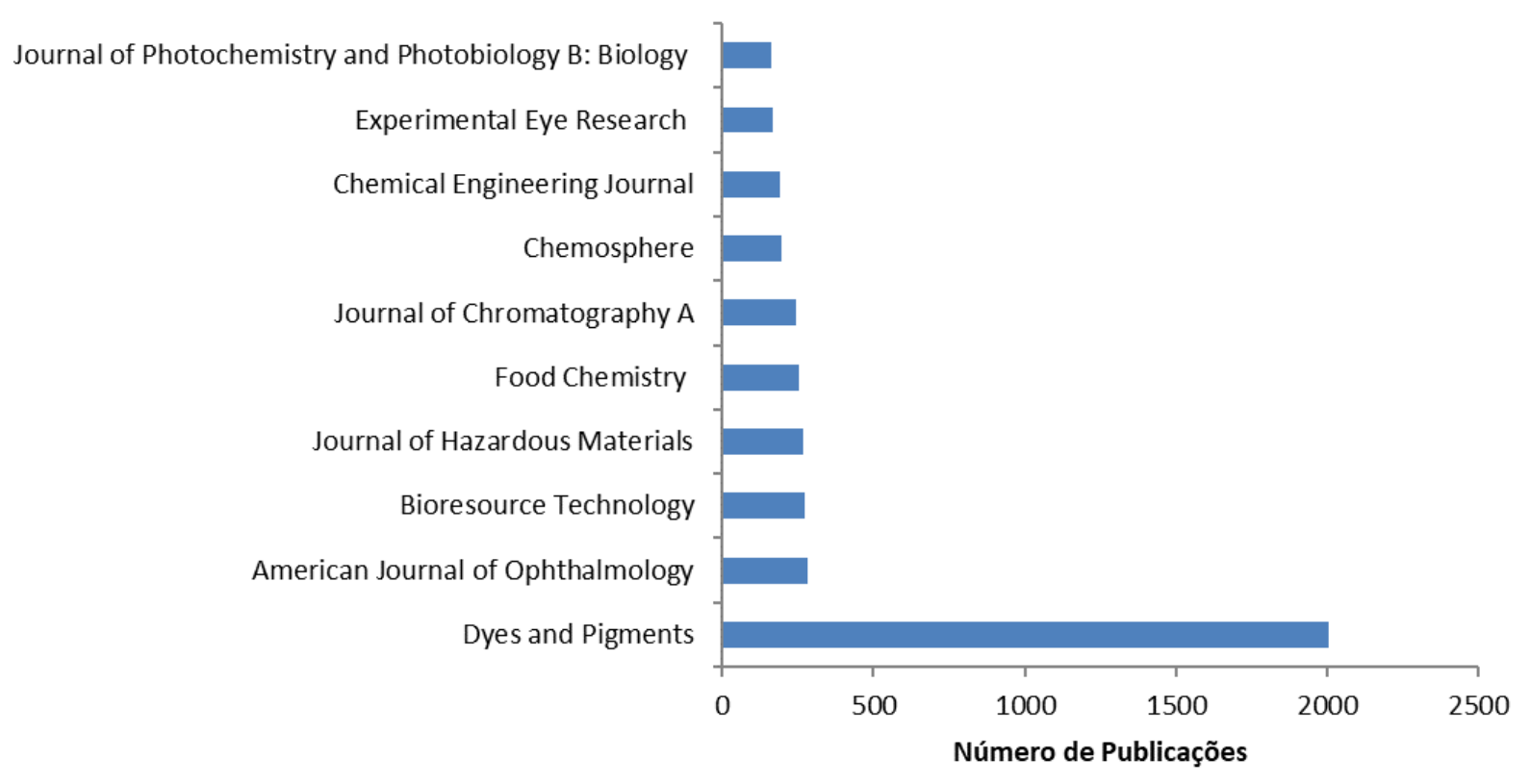

Fonte: Elaborada pelos autores deste artigo (2019)

Após a Revista Dyes and Pigments, uma das que mais se destacou na publicação de artigos científicos foi a Bioresource Technology com 270 artigos; seguida do Journal of Hazardous Materials com 269 artigos; Revista Food Chemistry com 255 artigos; Journal of Chromatography A com 243 artigos; Revista Chemosphere com 193 artigos; Chemical Engineering Journal com 191 
artigos e; por fim, o Journal of Photochemistry and Photobiology B: Biology com 162 artigos. Nota-se uma diferença significativa entre a Revista Dyes and Pigments, quando comparada às demais revistas, o que pode ser atribuído ao escopo específico dela.

\section{Considerações Finais}

A partir da análise dos resultados encontrados na prospecção, verificou-se que o desenvolvimento de métodos para o tratamento de corantes e pigmentos em meio aquoso é ainda pouco explorado no depósito de patentes, tendo alto potencial para gerar inovação. Porém, esse tema já é bastante explorado em outros meios de divulgação científica, como artigos científicos originais, artigos de revisão, anais de eventos etc.

Dos documentos de patentes encontrados o primeiro foi depositado em 1906 no Reino Unido tendo como titular Leon Lilienfeld. China, Reino Unido e Japão foram os países que mais se destacaram no depósito de patentes referentes a este tema, indicando que esses países estão investindo na apropriação do conhecimento na área. $\mathrm{O}$ país que mais se destacou no domínio tecnológico foi a China, com um total de 114 documentos de patentes. O Brasil não possui patentes depositadas sobre o tema, dentro do período de pesquisa deste trabalho.

Entre os Inventores, a empresa Ciba LTD e a pessoa física Henry Dreyfus merecem destaque, tendo depositado sete e cinco patentes, respectivamente. Quem mais investe no desenvolvimento de métodos para o tratamento de corantes e pigmentos de meio aquoso é o setor empresarial, com um total de $71 \%$. Entre os meios de divulgação científica, os artigos de pesquisa originais são os mais publicados, correspondendo a um total de 59\%. Entre as revistas que mais se destacam com publicações referentes ao tema, está a Dyes and Pigments que publicou até o ano de 2019 um total de 2003 artigos científicos.

A prospecção realizada mostrou que o Brasil, mesmo sendo possuidor de uma das maiores reservas de água doce do planeta, ainda não desenvolve métodos de tratamento de água contendo corantes e/ou pigmentos. Esse dado indica a importância do estabelecimento de grupos de pesquisa básica sobre processos e materiais para tratamento de água no país, com a posterior geração de documentos de patentes sobre o tema. Bem como o estabelecimento de projetos de pesquisa que desenvolvam novos processos ou que utilizem novos materiais para purificação de água.

Essa prospecção pode ser refinada para obtenção de dados sobre materiais utilizados para tratamento de água, tendo em vista o alto custo dos materiais atualmente utilizados, que dificultam, por exemplo, a purificação de água para reuso. Um outro desmembramento que pode ser feito a partir deste trabalho é a prospecção de processos de baixo custo para purificação de efluentes contaminados por pequenas empresas e negócios, como curtumes e matadouros, que geralmente não possuem recursos para impedir que seus efluentes sejam tratados antes de serem descartados nos esgotos.

\section{Referências}

BASE DE PATENTES ONLINE. 2019. Disponível em: http://www.inpi.gov.br/menu-servicos/ informacao/bases-de-patentes-online/. Acesso em: 5 jul. 2019 
BRITO, S. M. O. et al. Brazil nut shells as a new biosorbent to remove methylene blue and indigo carmine from aqueous solutions. Journal of Hazardous Materials, [S.1.], v. 174, p. 84-92, 2010.

CUNHA, G. L. D. As Relações Brasil-China: Ciência, Tecnologia e Inovação no Século XXI. 2017. 279p. Tese (Doutorado) - Universidade Federal do Rio de Janeiro, UFRJ, Rio de Janeiro, 2017.

DETONI, T. L.; DONDONI, P. C. A Escassez da água: um olhar global sobre a sustentabilidade e a consciência acadêmica. Revista Ciências Administrativas, [S.1.], v.14, p. 191-204, 2008.

DREYFUS FOUNDATION. 2019. Disponível em: https://www.dreyfus.org//. Acesso em: 9 jul. 2019.

ELBANNA, K. et al. Microbiological, histological, and biochemical evidence for the adverse effects of food azo dyes on rats. Journal of Food and Drug Analysis, [S.l.], p. 1-14, in press, 2017.

ENCYCLOPEDIA BRITANNICA, 2019. Disponível em: https://www.britannica.com/topic/Ciba-GeigyAG/. Acesso em: 9 jul. 2019.

ESPACENET. [Base de dados - Internet]. European Patent Office. 2019. Disponível em: https:// worldwide.espacenet.com/. Acesso em: 22 jan. 2019.

KHARAT, D. S. Preparing agricultural residue-based adsorbents for removal of dyes from effluents - A review. Brazilian Journal of Chemical Engineering, [S.I.], v. 1, p. 1-12, 2015.

KYZAS, G. Z.; FU, J.; MATIS, K. A. The Change from Past to Future for Adsorbent Materials in Treatment of Dyeing Wastewaters. Materials, [S.l.], v. 6, p. 5.131-5.158, 2013.

LODHI, R. S.; LAL, N. Dyes and pigments manufacturing industrial waste water treatment methodology. International Research Journal of Engineering and Technology (IRJET), [S.I.], v. 4, n. 2, p. 121-131, dec. 2017.

QUINTELLA, C. M. et al. Prospecção Tecnológica como uma Ferramenta Aplicada em Ciência e Tecnologia para se Chegar à Inovação. Revista Virtual de Química, [S.I.], v. 3, n. 5, p. 406-415, nov. 2011

SCIENCE DIRECT. [Base de dados - Internet]. Elsevier. 2019. Disponível em: www.sciencedirect. com. Acesso em: 5 set. 2019.

SILVA, H. R.; CID, A. L.; QUINTELLA, C. M. Prospecção tecnológica de patentes para identificação e quantificação dos componentes responsáveis pela fluorescência possíveis de serem encontrados no biodiesel. Cadernos de Prospecção, [S.l.], v. 8, n. 4, p. 700-712, out.-dez. 2015.

SUN, Q.; YANG, L. The adsorption of basic dyes from aqueous solution on modified peat-resin particle. Water Research, [S.1.], v. 37, n. 7, p. 1.535-1.544, abr. 2003.

WALTHALL, W.; STARK, J. The acute and chronic toxicity of two xanthene dyes, fluorescein sodium salt and phloxine B, to Daphnia pulex. Environmental Pollution, [S.1.], v. 104, n. 2, p. 207-215, fev. 1999.

YAGUB, M. T.; SEN, T. K.; ANG, H. M. Equilibrium, kinetics, and thermodynamics of methylene blue adsorption by pine tree leaves. Water, Air and soil Pollution, [S.l.], v. 223, p. 5.267-5.282, 2012.

YAGUB, M. T. et al. Dye and its removal from aqueous solution by adsorption: a review. Advances in Colloid and Interface Science, [S.1.], v. 209, p. 172-184, 2014. 


\section{Sobre os Autores}

\section{José Luiz Cunha Cordeiro}

E-mail:mujoseluis@hotmail.com

Graduado em Licenciatura em Química pela Universidade Estadual de Feira de Santana - UEFS. Atualmente desenvolve mestrado em Química Inorgânica pela Universidade Federal da Bahia - UFBA.

Endereço profissional: Rua Barão de Jeremoabo, s/n, Campus Universitário de Ondina, Salvador, Bahia. CEP: 40170-115.

\section{Suzana Modesto de Oliveira Brito}

E-mail:smobrito@gmail.com

Possui graduação em Química pela Universidade Federal da Bahia (1989), mestrado em Química pela Universidade Federal da Bahia (1992) e doutorado em Química pela Universidade Federal da Bahia (1999). Atualmente é professor titular da Universidade Estadual de Feira de Santana. Tem experiência na área de Química, com ênfase em Química Ambiental, atuando principalmente nos seguintes temas: poluição aquática, adsorção, zeólitos, carvão ativado e análise de água.

Endereço profissional: Av. Transnordestina, s/n, Novo Horizonte, Feira de Santana, Bahia. CEP: 44036-900. 